\title{
FK506 attenuates thymic output in patients with myasthenia gravis
}

\author{
Takao Mitsui ${ }^{1,2}$, Yukiko Kuroda ${ }^{1,2}$, Shu-ichi Ueno ${ }^{3}$, Naoko Matsui ${ }^{2}$, Ryuji Kaji²
}

\begin{abstract}
${ }^{1}$ Tokushima National Hospital, National Hospital Organization, Tokushima, Japan 2Department of Clinical Neuroscience, Institute of Health Biosciences, The University of Tokushima Graduate School, Tokushima, Japan

${ }^{3}$ Department of Psychiatry, Institute of Health Biosciences, The University of Tokushima Graduate School, Tokushima, Japan
\end{abstract}

Submitted: 28 December 2010

Accepted: 11 May 2011

Arch Med Sci 2013; 9, 6: 1090-1096

DOI: 10.5114/aoms.2013.39797

Copyright $\odot 2013$ Termedia \& Banach

\section{Abstract}

Introduction: Myasthenia gravis (MG) is an antibody-mediated, T-cell-dependent autoimmune disease. The symptoms are caused by high-affinity IgG against the muscle acetylcholine receptor (AChR) at the neuromuscular junction. The production of these antibodies in B-cells depends on AChR-specific CD4+ T-cells and the thymus gland seems to play a significant role in the pathogenesis of MG. Altered thymic T-cell export seems to be associated with a pathological mechanism in myasthenia gravis. Tacrolimus (FK506) has recently been used to treat MG.

Material and methods: We examined the effects of tacrolimus on thymic T-cell export in patients with MG. Sixteen patients with nonthymomatous and/or thymectomized MG were treated with oral administrations of tacrolimus. To assess the effect of tacrolimus on the thymic output, we assayed the levels of T-cell receptor excision circle (TREC), a molecular marker of thymus emigrants. Results: T-cell receptor excision circle was not significantly different from those in age-matched controls before tacrolimus therapy, but they were partially decreased 4 months after tacrolimus therapy. T-cell receptor excision circle levels were significantly decreased in the thymomatous group $(p<0.05)$, but not in the nonthymomatous group. Tacrolimus treatment significantly attenuated TREC levels in cultured CD4-CD $8^{+}$cells $(p<0.05)$, but total cell counts were not significantly changed.

Conclusions: These results indicate that TREC levels may become a marker of the curative effect of tacrolimus therapy for thymomatous MG, and that tacrolimus suppresses not only activating T-lymphocytes, but also naïve T-cells.

Key words: T cell receptor excision circle, T-cell receptor excision circle, lymphocytes, cell culture.

\section{Introduction}

Myasthenia gravis (MG) is an antibody-mediated, T-cell-dependent autoimmune disease. The symptoms are caused by high-affinity IgG against the muscle acetylcholine receptor (AChR) at the neuromuscular junction [1-3]. The production of these antibodies in B-cells depends on AChR-specific CD4+ T-cells $[4,5]$. The thymus gland seems to play a significant role in the pathogenesis of MG. Thymic abnormalities exist in a high proportion (approximately 75\%) of myasthenic patients [1]. Of these patients, $85 \%$ have hyperplasia and the rest thymomas [1]. Although no pathological basis for the association between thymomas and an autoimmune

\author{
Corresponding author: \\ Takao Mitsui MD \\ Tokushima National Hospital \\ National Hospital \\ Organization \\ 1354 Shikiji, Kamojima \\ Yoshinogawa \\ Tokushima 776-8585, Japan \\ Phone: +81 883242161 \\ Fax: +81 883248661 \\ E-mail: tmitsui@tokushima. \\ hosp.go.jp
}


mechanism has been identified, some evidence suggests that myasthenic patients with thymoma harbor different immunoregulatory abnormalities from those without it $[6,7]$. Recent evidence indicates that lymphocyte composition of peripheral blood differs between patients with thymomatous $M G$ and those with nonthymomatous $M G[1,3,7]$. Thymoma is the only tumor proven to generate mature T-cells from immature precursors. In thymomatous MG, mature T-cells with autoreactive activities may leave the thymus for the bloodstream and persist in the periphery for more than 10 years $[6,8]$. Phenotypic and T-cell receptor excision circle (TREC) analysis confirmed a thymic origin of the expanded naïve T-cell subset. An analysis of the Tcell receptor repertoire showed the reconstitution of an overall broader clonal diversity, and TREC was used as a marker of thymic output. T-cell receptor excision circle levels were significantly raised in peripheral lymphocytes in thymomatous MG patients and decreased after thymectomy $[6,8,9]$. Recent observations indicate that altered thymic Tcell export may be associated with a pathological mechanism in some autoimmune diseases [10-17].

During the past two decades, the outlook for MG patients has improved dramatically as a result of advances in treatment. The most important methods used in the treatment of MG include anticholinesterase agents, thymectomy, immunosuppression with glucocorticoids, and plasma exchange [1]. Tacrolimus (FK506) has recently been used to treat MG [13-17]. It is an immunosuppressive agent similar to cyclosporin A that inhibits the action of calcineurin, a serine/threonine phosphatase, thereby suppressing interleukin-2 production $[18,19]$ and Tcell proliferation [20]. We herein report the effects of tacrolimus on thymic T-cell export in patients with MG.

\section{Material and methods}

\section{Clinical assessment}

The subjects of this study were 16 patients with myasthenia gravis. All were selected from Japanese patients who had been treated at Tokushima University Hospital from April 2006 to January 2008 and who agreed to participate in the study. The 16 patients fulfilled the following criteria at pretreatment: (1) a muscle weakness in ocular and limb muscle groups that was aggravated by exercise and relieved by rest; (2) a significant rise in anti-AChR titers; (3) a significant decrement (over 10\%) on repetitive nerve stimulation; (4) a positive edrophonium chloride test; (5) a negative history of administration with penicillamine. The classification of MG was performed according to Myasthemia Gravis Foundation of America (MGFA) [21], and all cases were classified into types I, II, or III.
Twelve patients underwent extended thymectomy with a transsternal approach. Thymoma was found in 6 patients, hyperplasia in two, and the examination was unremarkable in the others. Invasive thymoma was not found in the present patients. All patients received oral administrations of tacrolimus (3 mg/day; $1 \mathrm{mg}$ was taken three times a day). Other therapies, such as anticholinesterase and corticosteroids, remained unchanged during the tacrolimus therapy. Seven patients received corticosteroid therapy. The patients were evaluated 2 and 4 months after treatment by measurement of the quantified myasthenia gravis disability score (MG score) ranging from 0 to 39 [22] and an antiacetylcholine receptor (AchR) antibody titer. For measurement of the MG score, muscle strength of all the patients was assessed by a neurologist who was blinded to their clinical information. Laboratory examinations were also performed before and after treatment, including peripheral blood cell count, transaminases, cholesterol, and blood sugar. Plasma concentrations of tacrolimus were assayed 2 and 4 months after the therapy.

Control samples were obtained from 12 agematched volunteers ( 5 men and 7 women). Their age was $60.5 \pm 5.2$ years (mean \pm SE). They did not have diseases except hypertension or family history of neuromuscular disorders. After obtaining approval from the Tokushima University Hospital Ethics Committee following their ethical consideration, we gave an oral explanation about Vague, and written agreement was obtained.

\section{Separation of $\mathrm{CD} 4^{+}$and $\mathrm{CD} 8^{+}$cell populations}

Separation of $\mathrm{CD}^{+}$and $\mathrm{CD}^{+}$cell populations was carried out according to the previous report [6]. In brief, mononuclear cells were separated from peripheral blood using Lymphoprep (Nycomed, UK). Magnetic cell-sorting (MACS ${ }^{\circledR}$ ) (Miltenyi-Biotec, Surrey, UK) columns were used as per the manufacturer's protocol to positively select $\mathrm{CD}^{+}$and then $\mathrm{CD}^{+}$ lymphocytes so that any double positive $\mathrm{CD} 4^{+} / \mathrm{CD}^{+}$ cells were included in the $\mathrm{CD} 8^{+}$fraction. After the two step of affinity columns, the lymphocytes were classified in four fractions: $\mathrm{CD}^{+} / \mathrm{CD}^{+}, \mathrm{CD}^{-} / \mathrm{CD}^{+}$, $\mathrm{CD}^{+} / \mathrm{CD}^{-}{ }^{-}$, and $\mathrm{CD} 4^{-} / \mathrm{CD}^{-}$. The cells were counted using a hemocytometer. Some cells were used for primary culture, and the remaining cells were stored at $-80^{\circ} \mathrm{C}$ until PCR analysis.

\section{Quantification of T-cell receptor excision circle (TREC) DNA}

Genomic DNA was extracted using a QIAamp Blood Kit (Qiagen, Hilden, Germany) according to the manufacturer's protocol. For quantification of TRECS, we used a Light Cycler PCR and detection system (Roche Diagnostics, Mannheim, Germany) 
according to the previous report [23]. Primers (5'CTC TCC AAG GCA AAA TGG G, 5'-GTG ACA TGG AGG GCT GAA C) were used to detect a defined region of the $\delta$ Rec- $\psi J \alpha$ signal joint TREC, which is generated after the TCR- ${ }^{-}$gene rearrangement. For the amplicon detection, the Light Cycler DNA FastStart Master Hybridization Probes Kit was used. Two different oligonucleotides were hybridized to a specific sequence of the $\delta$ Rec- $\psi J \alpha$ signal joint TREC. One probe was labeled at the 5'-end with the Light Cycler-Red 640 fluorophore (5'-AAA ACC AGA GGT GTC AGC ATG GT p), the other at the 3'-end with fluorescein (5'-CCA CAG GAG TGG GCA CCT TTA C X). The polymerase chain reaction (PCR) was run under standard conditions with $5 \mathrm{mM}$ magnesium chloride and 12.5 pmol primers performing an initial 9 min at $95^{\circ} \mathrm{C}$ for FastStart Taq activation followed by 45 cycles of repeated denaturation $\left(1 \mathrm{~s}\right.$ at $95^{\circ} \mathrm{C}$ ), annealing $\left(15 \mathrm{~s}\right.$ at $\left.57^{\circ} \mathrm{C}\right)$ and enzymatic chain extension $\left(25 \mathrm{~s}\right.$ at $\left.72^{\circ} \mathrm{C}\right)$. External standardization was performed using a plasmid containing the $\delta \operatorname{Rec}-\psi J \alpha$ signal joint TREC break point. Concentrations of $\delta$ Rec- $\psi J \alpha$ signal joint TREC DNA in the blood specimens were calculated comparing the cycle numbers of the log-linear phase of the samples with the cycle numbers of the external standards. All samples were run in duplicate and if there was greater than 10\% discrepancy between duplicates, the assay was repeated. No-template controls were always included and never produced measurable fluorescence. T-cell receptor excision circle levels are expressed as TREC DNA copies per microgram of DNA. Cell lysates were checked for consistency of DNA content using $\beta$-actin PCR; interassay variability was found to be less than $10 \%$ of the mean for the same sample in different assays.

\section{Mononuclear cell culture}

Single-positive cells (CD4 ${ }^{+} \mathrm{CD} 8^{-}$and $\mathrm{CD} 4^{-} \mathrm{CD} 8^{+}$ cells) were resuspended in RPMI 1640 containing 10\% fetal bovine serum, $100 \mathrm{lU} / \mathrm{ml}$ penicillin, and $100 \mathrm{\mu g} / \mathrm{ml}$ streptomycin, according to the previous report [24]. The cells were incubated for $72 \mathrm{~h}$ in $5 \%$ $\mathrm{CO}_{2} /$ air at $37^{\circ} \mathrm{C}$ in a humidified chamber in the presence $(10 \mathrm{ng} / \mathrm{ml}$ and $1000 \mathrm{ng} / \mathrm{ml})$ or absence of FK506. The cell count was measured with a hemocytometer prior to plating cells, and $72 \mathrm{~h}$ after FK506 treatment.

\section{Statistical analysis}

We used StatView for Windows (version 5.0) for statistical analysis. Nonpaired data and paired data were analyzed by the nonparametric Mann-Whitney $U$ test and Wilcoxon's signed rank test, respectively.

\section{Results}

This study included 16 patients (Table I). The ages ranged from 33 to 84 years, and the mean $( \pm \mathrm{SE})$ age was $63.6( \pm 3.2)$ years. Disease duration was from 2 to 33 years, and mean duration was 14.1 $( \pm 10.0)$ years. Figure 1 shows the profiles of titers

Table I. Summary of patients

\begin{tabular}{|c|c|c|c|c|c|c|c|c|}
\hline Patient & Age & Gender & MGFA & $\begin{array}{c}\text { Duration } \\
\text { [years] }\end{array}$ & $\begin{array}{c}\mathrm{PSL} \\
{[\mathrm{mg} / \mathrm{dl}]}\end{array}$ & $\begin{array}{c}\text { AChR Ab } \\
{[\mathrm{nmol} / \mathrm{l}]}\end{array}$ & Thymectomy & Thymoma \\
\hline 1 & 63 & $M$ & $\| \mathrm{A}$ & 4 & 7.5 & 1.1 & & \\
\hline 2 & 64 & $\mathrm{~F}$ & $\| A$ & 6 & & 24 & + & \\
\hline 3 & 60 & $\mathrm{~F}$ & $\| \mathrm{A}$ & 31 & 7.5 & 77 & + & + \\
\hline 4 & 61 & $M$ & 1 & 17 & & 0.3 & & \\
\hline 5 & 81 & $\mathrm{~F}$ & IIIA & 31 & 10 & 8.2 & + & \\
\hline 6 & 63 & $M$ & $\| A$ & 10 & & 24 & + & \\
\hline 7 & 72 & $\mathrm{~F}$ & $\| A$ & 33 & & 10 & + & + \\
\hline 8 & 67 & $\mathrm{~F}$ & $\| A$ & 6 & 15 & 4.2 & + & + \\
\hline 9 & 72 & $\mathrm{~F}$ & IIIA & 20 & & 480 & + & \\
\hline 10 & 47 & $\mathrm{~F}$ & $\| A$ & 10 & & 17 & + & \\
\hline 11 & 65 & $\mathrm{~F}$ & $I I A$ & 19 & 7.5 & 21 & + & \\
\hline 12 & 48 & $F$ & IIIA & 8 & 2.5 & 1.8 & + & + \\
\hline 13 & 74 & $\mathrm{~F}$ & IIB & 10 & 7.5 & 22 & & \\
\hline 14 & 33 & $F$ & IIB & 3 & & 120 & & \\
\hline 15 & 84 & $M$ & $\| A$ & 12 & & 40 & + & + \\
\hline 16 & 63 & $M$ & $\| A$ & 7 & & 65 & + & + \\
\hline
\end{tabular}

MGFA - myasthenia gravis foundation of America, PSL - prednisolone, AChR Ab-acetylcholine receptor antibody 
A

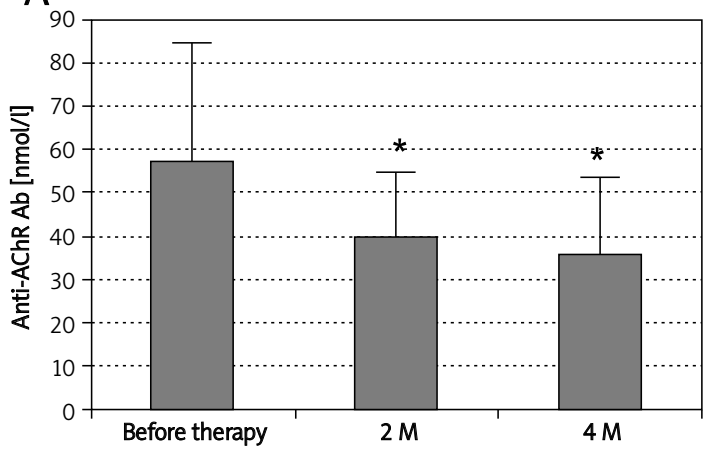

B

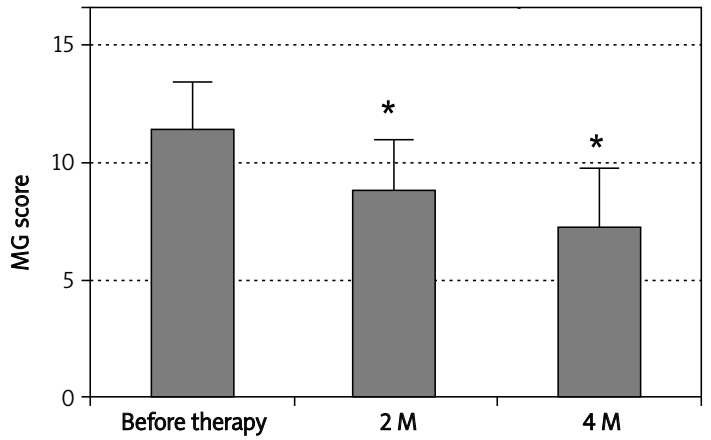

Figure 1. Titers of antiacetylcholine receptor (anti-AChR) antibody (A) and MG (B) scores in patients with myasthenia gravis 2 months ( $2 M$ ) and 4 months ( $4 M$ ) after oral administration of tacrolimus ( $3 \mathrm{mg} /$ day). After tacrolimus therapy, titers of anti-AChR and MG scores significantly improved ${ }^{*} p<0.05$

of anti-AChR antibody and MG scores. Titers of antiAChR antibody (0 M, 57.23 $\pm 29.3 ; 2 \mathrm{M}, 39.5 \pm 18.3$; $4 \mathrm{M}, 35.8 \pm 17.7$ (mean $\pm \mathrm{SE})$ ) and $M G$ scores $(0 \mathrm{M}$ $11.7 \pm 1.9 ; 2 \mathrm{M}, 8.2 \pm 2.1 ; 4 \mathrm{M}, 7.2 \pm 2.3$ (mean $\pm \mathrm{SE}$ )) were significantly decreased after tacrolimus therapy $(p<0.05)$.

We assessed TREC levels in single double-positive cells $\left(\mathrm{CD} 4^{+} \mathrm{CD} 8^{+}\right)$, positive cells $\left(\mathrm{CD} 4^{+} \mathrm{CD} 8^{-}\right.$and $\mathrm{CD} 4^{-}$ $\mathrm{CD} 8^{+}$cells), and double-negative cells (CD4 $\left.{ }^{-} \mathrm{CD} 8^{-}\right)$. Control samples were obtained from age-matched volunteers $(n=12)$. As shown in Figure 2 A, the TREC levels of MG patients (CD4+CD8 ${ }^{+}, 1515 \pm 436$ copy/ $\mu \mathrm{g}$

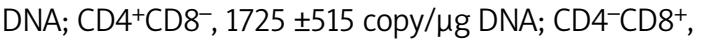
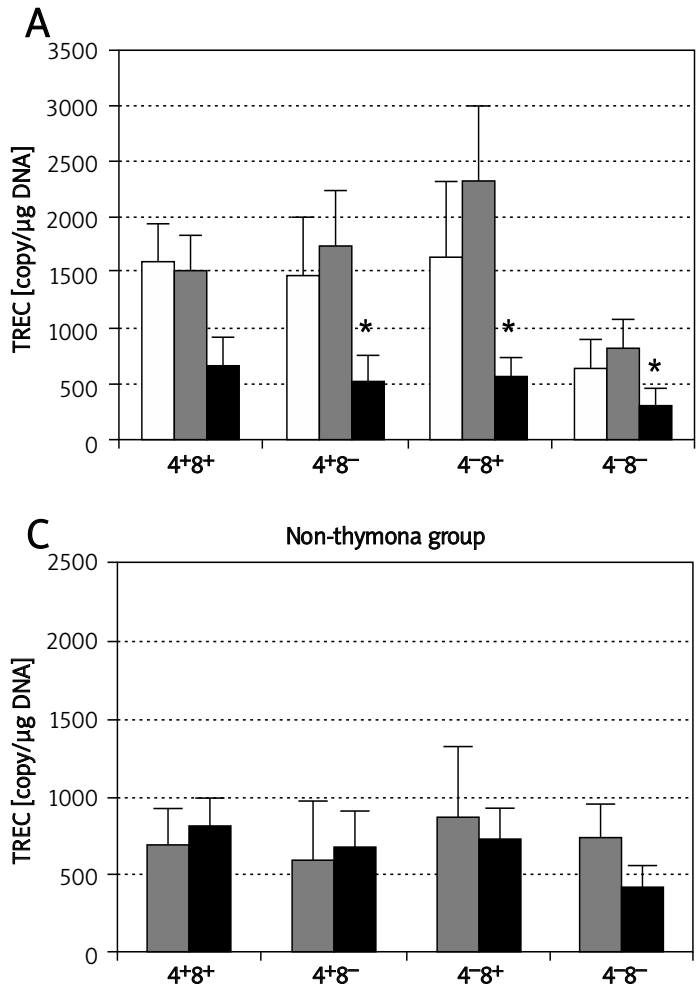

$2322 \pm 772$ copy/ug DNA; CD4-CD8-, $813 \pm 230$ copy/ $\mu \mathrm{g}$ DNA) were not significantly different from those of controls (CD4 ${ }^{+} \mathrm{CD}^{+}, 1585 \pm 351$ copy/ $\mu \mathrm{g}$ DNA;

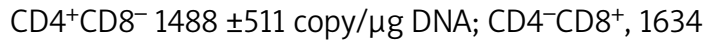

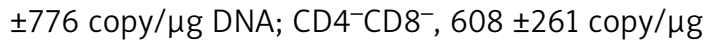
DNA). However, the levels in single-positive cells and double-negative cells were significantly decreased 4 months after tacrolimus therapy $(p<0.05)$

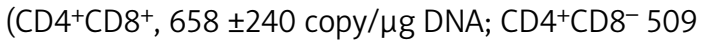

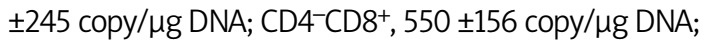
CD4-D8-, $310 \pm 127$ copy/ug DNA).

We further examined the effect of thymoma or corticosteroid therapy on TREC levels in patients

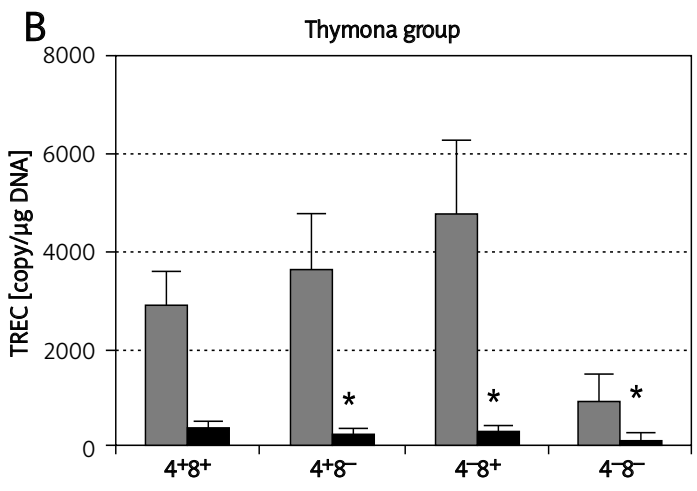

Figure 2. T-cell receptor excision circle (TREC) levels in single double-positive cells $\left(\mathrm{CD} 4^{+} \mathrm{CD} 8^{+}\right)$, positive cells (CD4 ${ }^{+} \mathrm{CD} 8^{-}$and $\mathrm{CD} 4^{-} \mathrm{CD} 8^{+}$cells), and doublenegative cells ( $\left.C D 4^{-} \mathrm{CD} 8^{-}\right)$in patients with $M G$ and age-matched controls. A - TREC levels in patients with MG (columns with slant lines) were not significantly different from those of age-matched controls (open columns), but the levels in single-positive cells and double-negative cells were significantly decreased $4 \mathrm{M}$ after tacrolimus therapy (closed columns). B and C-TREC levels in patients with thymomatous MG (thymoma group, B) and nonthymomatous MG (nonthymoma group, C). The TREC levels in all types of lymphocytes were significantly decreased after therapy in the thymoma group (B), but not in the nonthymoma group (C) ${ }^{*} p<0.05$ 
with MG. In the thymoma group, TREC levels

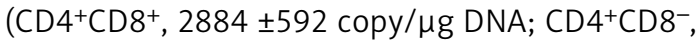

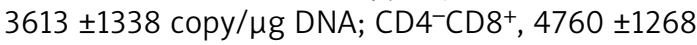

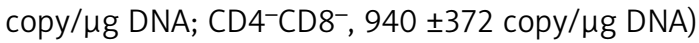
were significantly decreased after tacrolimus ther-

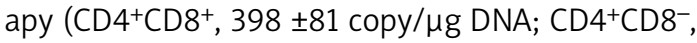
$243 \pm 108 \mathrm{copy} / \mu \mathrm{g}$ DNA; CD4-CD8 ${ }^{+}, 266 \pm 65.3$

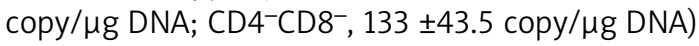
$(p<0.05$, Figure $2 \mathrm{~B})$. In the nonthymoma group,

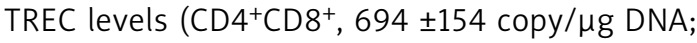

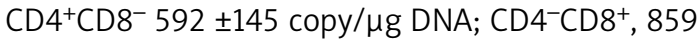

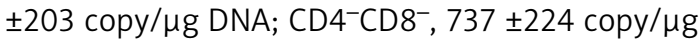
DNA) were not different after tacrolimus therapy $\left(\mathrm{CD}^{+}{ }^{+} \mathrm{CD}^{+}, 813 \pm 280\right.$ copy/ug DNA; $\mathrm{CD}^{+}{ }^{+} \mathrm{CD}^{-}, 685$ $\pm 283 \mathrm{copy} / \mu \mathrm{g}$ DNA; CD4 ${ }^{-} \mathrm{CD}^{+}, 721 \pm 235 \mathrm{copy} / \mu \mathrm{g}$

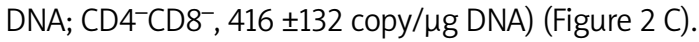
In the corticosteroid group, TREC levels $\left(\mathrm{CD} 4^{+} \mathrm{CD} 8^{+}\right.$,

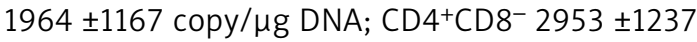

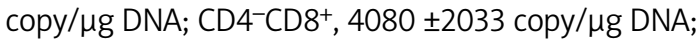

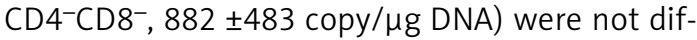
ferent after tacrolimus therapy $\left(\mathrm{CD} 4^{+} \mathrm{CD} 8^{+}, 508 \pm 160\right.$

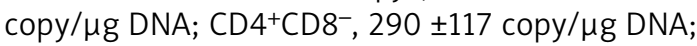

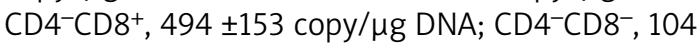

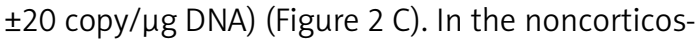
teroid group, TREC levels $\left(\mathrm{CD}^{+}{ }^{+} \mathrm{CD}^{+}, 1166 \pm 442\right.$

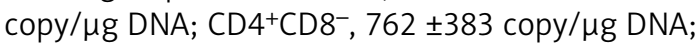
$\mathrm{CD}^{-}{ }^{-} \mathrm{CD} 8^{+}, 954 \pm 445 \mathrm{copy} / \mu \mathrm{g}$ DNA; CD4-CD8- 760 \pm 475 copy/ $\mu$ g DNA) also were not different after
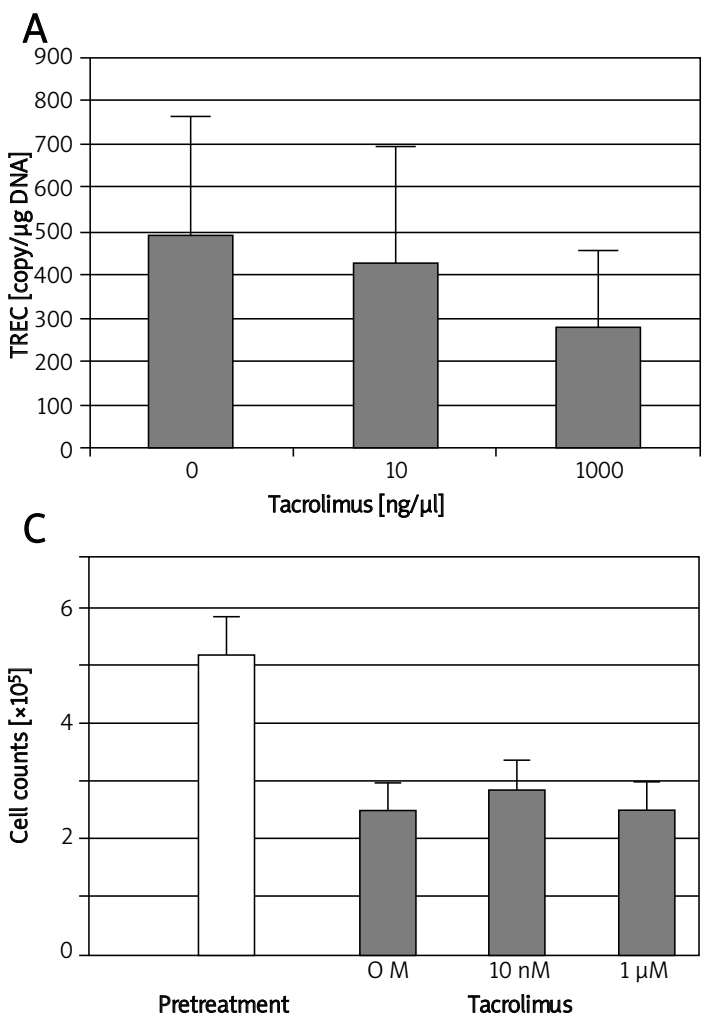

tacrolimus therapy $\left(\mathrm{CD} 4^{+} \mathrm{CD} 8^{+}, 774 \pm 416\right.$ copy/ $\mu \mathrm{g}$

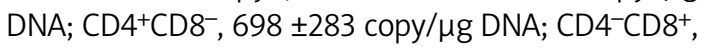
$594 \pm 219$ copy/ug DNA; CD4-CD8-, $470 \pm 254$ copy/ $\mu \mathrm{g}$ DNA) (Figure $2 \mathrm{C}$ ). The patients with myasthenia gravis took FK506 for at least 6 months. During FK506 treatment, laboratory data and clinical findings did not show any side effects including infection, liver and kidney dysfunction, hyperkalemia, hyperglycemia, and diabetes mellitus.

Next we examined the direct effect of tacrolimus on cultured T-lymphocytes from patients with MG. Single-positive cells were used in this study, since double-negative/-positive cells were unable to secure sufficient cell counts. Tacrolimus treatment did not significantly change TREC levels (Figure $3 \mathrm{~A}$ ) or total cell counts (Figure $3 \mathrm{C}$ ) in $\mathrm{CD}^{+}{ }^{+} \mathrm{CD} 8^{-}$cells. On the other hand, tacrolimus treatment significantly attenuated TREC levels of $\mathrm{CD}^{-}{ }^{-} \mathrm{CD} 8^{+}$cells

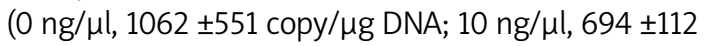

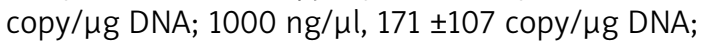
$p<0.05$ ) (Figure $3 \mathrm{~B}$ ), but total cell counts were not significantly changed (Figure $3 \mathrm{D}$ ).

\section{Discussion}

The thymus gland, an indispensable organ for the deletion of autoreactive T-cells, seems to play a significant role in the pathogenesis of MG. Recent
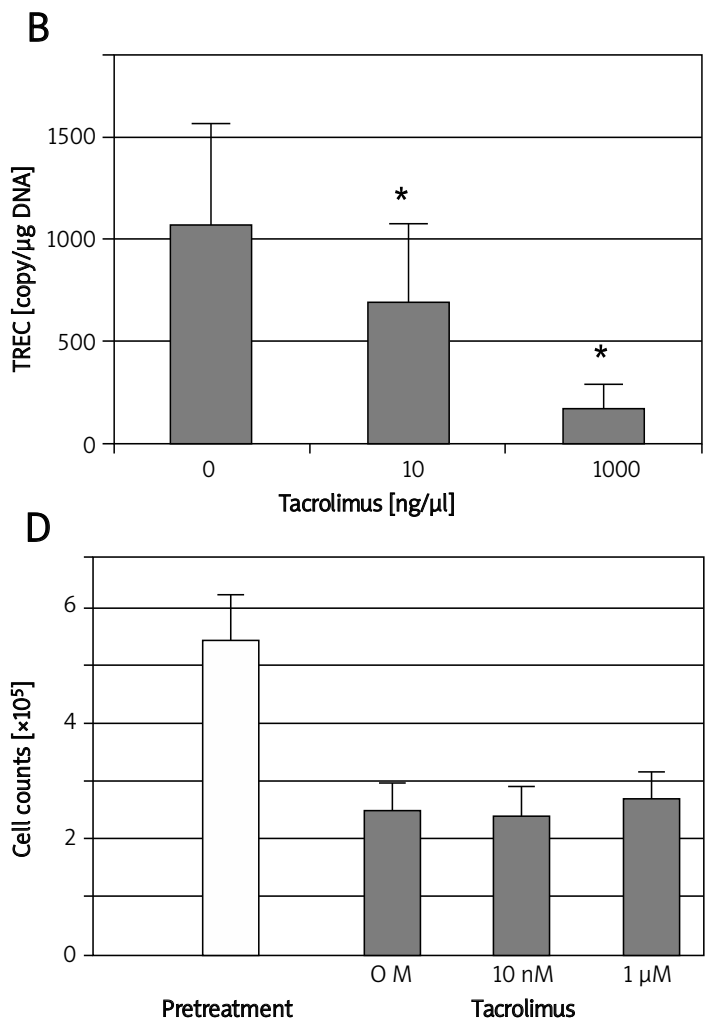

Figure 3. The effect of tacrolimus on cultured $C D 4^{+} C D 8^{-}$cells ( $A$ and $C$ ) and $C D 4^{-} C D 8^{+}$cells (B and D). Tacrolimus treatment $\left(72 \mathrm{~h}\right.$ ) did not significantly change T-cell receptor excision circle levels in $\mathrm{CD}^{+}{ }^{+} \mathrm{CD} 8^{-}$cells (A), but it significantly decreased the levels in $\mathrm{CD}^{-} \mathrm{CD}^{+}$cells (B). Cell counts were not changed by tacrolimus treatment ${ }^{*} p<0.05$ 
evidence indicates that lymphocyte composition of peripheral blood differs between patients with thymomatous $M G$ and those with nonthymomatous MG $[1,3,7]$. In thymomatous MG, naïve T-cells as well as TRECs were increased in the peripheral bloodstream, and the TREC levels decreased after thymectomy $[6,8,9]$. Given these facts, we find that the enhanced thymopoiesis is quite likely to be related to the development of the autoimmune mechanism. However, it has not been clarified whether this hypothesis is true in nonthymomatous MG or whether TREC becomes a general disease marker of $M G[6,9]$. In the present study, we investigated whether tacrolimus therapy alters TREC levels in patients with MG. It is well known that TREC levels depend on aging; they remain high for the first 20 years of life and gradually decrease thereafter as the thymus atrophies [25]. We compared TREC levels between patients with MG and age-matched controls. Although TREC levels in patients were not significantly different from those in age-matched controls, we found that tacrolimus therapy significantly decreased TREC levels in patients with MG. Taken together, titers of antiacetylcholine receptor antibody and MG scores were significantly decreased. It is noteworthy that tacrolimus therapy significantly attenuated TREC levels in the thymomatous group, but not in the nonthymomatous group. The present study included 6 thymomatous patients who underwent thymectomy. We previously reported that tacrolimus has an especially beneficial effect on clinical symptoms in thymomatous MG [13]. These results indicate that TREC levels may become a marker of the curative effect of the tacrolimus in thymomatous MG.

T-cell receptor excision circle production seems to play important roles in the development of autoimmune diseases, but the precise mechanism is not postulated and may be complicated; TREC levels are reportedly increased in patients with autoimmune thyroid disease [10] and with thymomatous $M G[6,8,9]$ and decreased in patients with multiple sclerosis [26] and juvenile arthritis [27]. We found that corticosteroid therapy did not modulate the effect of tacrolimus therapy on TREC levels. This is concordant with the previous report that TREC levels might not depend on the immunosuppressive therapy using prednisone and azathioprine [9]. In the present study, we examined the direct effect of tacrolimus on cultured T-lymphocytes. It did not show the toxic effect on them, but it significantly decreased the TREC levels in $\mathrm{CD}^{-}{ }^{-} \mathrm{CD} 8^{+}$cells. It is well known that tacrolimus inhibits the activation of T-lymphocytes via the suppression of calcineurin [20]. It is confirmed in many institutions that lowdose FK506 is effective in myasthenia gravis. Recently Minami et al. reported data from 9 patients with steroid-dependent generalized MG treat- ed with low-dose tacrolimus (2-3 mg/day) for 5 years [28]. Following treatment with tacrolimus, the mean MG activities of daily living score improved and mean dose of prednisolone could also be reduced. Zhao et al. reported that low-dose tacrolimus ( $3 \mathrm{mg} /$ day) for 24 weeks reduced steroid dosage and levels of cytokines, such as interferon- $\gamma$ (IFN- $\gamma$ ), interleukin 2, 10 and 13 (IL-2, IL-10, and IL-13) [29]. The present results suggest that it suppresses not only activating T-lymphocytes, but also naïve T-cells. We could not identify the molecular mechanism, but the suppressive effect of tacrolimus on naïve T-cells and thymic output may suggest the unique immunosuppressive action of this drug.

\section{References}

1. Vincent A, Drachman DB. Myasthenia gravis. In: Neuromuscular disorders. Pourmand R, Harati Y (eds.) Lippincott Williams \& Wilkins, Philadelphia 2001; 159-88.

2. Lewis RA, Selwa JF, Lisak RP. Myasthenia gravis: immunological mechanisms and immunotherapy. Ann Neurol 1995; 37: S51-62.

3. Vincent A, Palace J, Hilton-Jones D. Myasthenia gravis. Lancet 2001; 357: 2122-8.

4. Kaul R, Shenoy M, Goluszko E, Christadoss P. Major histocompatibility complex class II gene disruption prevents experimental autoimmune myasthenia gravis. J Immunol 1994; 152: 3152-7.

5. Zhang GX, Xiao BG, Bakhiet M, et al. Both CD4+ and CD8+ $T$ cells are essential to induce experimental autoimmune myasthenia gravis. J Exp Med 1996; 184: 349-55.

6. Buckley C, Douek D, Newsom-Davis J, Vincent A, Willcox N. Mature, long-lived CD4+ and CD8+ $T$ cells are generated by the thymoma in myasthenia gravis. Ann Neurol 2001; 50: 64-72.

7. Reinhardt C, Melms A. Normalization of elevated CD4/CD8- (double- negative) T cells after thymectomy parallels clinical remission in myasthenia gravis associated with thymic hyperplasia but not thymoma. Ann Neurol 2000; 48: 603-8.

8. Hoffacker V, Schultz A, Tiesinga JJ, et al. Thymomas alter the $T$ cell subset composition in the blood: a potential mechanism for thymoma-associated autoimmune disease. Blood 2000; 96: 3872-9.

9. Sempowski G, Thomasch J, Gooding M, et al. Effect of thymectomy on human peripheral blood T cell pools in myasthenia gravis. J Immunol 2001; 166: 2808-17.

10. Armengol MP, Sabater L, Fernández M, et al. Influx of recent thymic emigrants into autoimmune thyroid disease glands in humans. Clin Exp Immunol 2008; 153: 338-50.

11. Stinissen P. Analyses of immunosenescent markers in patients with autoimmune disease. Clin Immunol 2007; 123: 209-18.

12. Thewissen M, Linsen L, Somers V, Geusens P, Raus J, Stinissen P. Premature immunosenescence in rheumatoid arthritis and multiple sclerosis patients. Ann N Y Acad Sci 2005; 1051: 255-62.

13. Mitsui T, Kunishige M, Ichimiya M, Shichijo K, Endo I, Matsumoto T. Beneficial effect of tacrolimus on myasthenia gravis with thymoma. Neurologist 2007; 13: 83-6.

14. Tanaka S, Hirano T, Saito T, Wakata N, Oka K. P-glycoprotein function in peripheral blood mononuclear cells of 
myasthenia gravis patients treated with tacrolimus. Biol Pharm Bull 2007; 30: 291-6.

15. Ponseti JM, Gamez J, Azem J, López-Cano M, Vilallonga R Armengol M. Tacrolimus for myasthenia gravis: a clinical study of 212 patients. Ann N Y Acad Sci 2008; 1132: 254-63.

16. Tada M, Shimohata T, Tada M, et al. Long-term therapeutic efficacy and safety of low-dose tacrolimus (FK506) for myasthenia gravis. J Neurol Sci 2006; 247: 17-20.

17. Utsugisawa K, Nagane $Y$, Yonezawa H, Obara D, Kondoh R, Tohgi $\mathrm{H}$. Effects of FK506 on myasthenia gravis patients with high interleukin-2 productivity in peripheral blood mononuclear cells. Muscle Nerve 2003; 27: 245-8.

18. Bierer BE, Holländer G, Fruman D, Burakoff SJ. Cyclosporin $A$ and FK506: molecular mechanisms of immunosup pression and probes for transplantation biology. Curr Opin Immunol 1993; 5: 763-73.

19. Allison AC. Immunosuppressive drugs: the first 50 years and a glance forward. Immunopharmacol 2000; 47; 63-83.

20. Schreiber SL, Crabtree GR. The mechanism of action of cyclosporin A and FK506. Immunol Today 1992; 13: 136-42.

21. Jaretzki III A, Barohn RJ, Ernstoff RM, et al. Myasthenia gravis. Recommendations for clinical research standers. Neurology 2000; 55: 16-23.

22. Tindall RSA, Rollins JA, Phillips JT, Greenlee RG, Wells L, Belendiuk G. Preliminary results of a double-blind, randomized, placebo-controlled trial of cyclosporine in myasthenia gravis. New Engl J Med 1987; 316: 719-24.

23. Loeffler J, Bauer R, Hebart H, et al. Quantification of T-cell receptor excision circle DNA using fluorescence resonance energy transfer and the LightCycler system. J Immunol Methods 2002; 271: 167-75.

24. Horigome A, Hirano T, Oka K. Tacrolimus-induced apoptosis and its prevention by interleukins in mitogen activated human peripheral-blood mononuclear cells. Immunopharmacology 1998; 39: 21-30.

25. Douek DC, McFarland RD, Keiser PH, et al. Changes in thymic function with age and during the treatment of HIV infection. Nature 1998; 396: 690-5.

26. Hug A, Korporal M, Schröder I, et al. Thymic export function and $T$ cell homeostasis in patients with relapsing remitting multiple sclerosis. J Immunol 2003; 171: 432-7.

27. Prelog $M$, Schwarzenbrunner N, Sailer-Höck $M$, et al. Premature aging of the immune system in children with juvenile idiopathic arthritis. Arthritis Rheum 2008; 58: 2153-62.

28. Minami N, Fujiki N, Doi S, et al. Five-year follow-up with low-dose tacrolimus in patients with myasthenia gravis. J Neurol Sci 2011; 300: 59-62.

29. Zhao CB, Zhang X, Zhang H, et al. Clinical efficacy and immunological impact of tacrolimus in Chinese patients with generalized myasthenia gravis. Int Immunopharmacol 2011; 11: 519-24. 